\title{
Tryptophan overloading activates brain regions involved with cognition, mood and anxiety
}

\author{
LUANA C.A. SILVA ${ }^{1}$, MILENA B. VIANA ${ }^{2}$, JOSÉ S. ANDRADE ${ }^{2}$, MELYSSA A. SOUZA ${ }^{2}$, \\ ISABEL C. CÉSPEDES ${ }^{2}$ and VÂNIA D'ALMEIDA ${ }^{1}$
}

${ }^{1}$ Departamento de Psicobiologia, Universidade Federal de São Paulo, Rua Napoleão de Barros, 925, $3^{\circ}$ andar, 04023-062 São Paulo, SP, Brazil

${ }^{2}$ Departamento de Biociências, Universidade Federal de São Paulo, Rua Silva Jardim, 136, $3^{\circ}$ andar, 11060-001 Santos, SP, Brazil

Manuscript received on March 31, 2016; accepted for publication on December 18, 2016

\begin{abstract}
Tryptophan is the only precursor of serotonin and mediates serotonergic activity in the brain. Previous studies have shown that the administration of tryptophan or tryptophan depletion significantly alters cognition, mood and anxiety. Nevertheless, the neurobiological alterations that follow these changes have not yet been fully investigated. The aim of this study was to verify the effects of a tryptophan-enriched diet on immunoreactivity to Fos-protein in the rat brain. Sixteen male Wistar rats were distributed into two groups that either received standard chow diet or a tryptophan-enriched diet for a period of thirty days. On the morning of the 31 st day, animals were euthanized and subsequently analyzed for Fos-immunoreactivity (Fos-ir) in the dorsal and median raphe nuclei and in regions that receive serotonin innervation from these two brain areas. Treatment with a tryptophan-enriched diet increased Fos-ir in the prefrontal cortex, nucleus accumbens, paraventricular hypothalamus, arcuate and ventromedial hypothalamus, dorsolateral and dorsomedial periaqueductal grey and dorsal and median raphe nucleus. These observations suggest that the physiological and behavioral alterations that follow the administration of tryptophan are associated with the activation of brain regions that regulate cognition and mood/anxiety-related responses.
\end{abstract}

Key words: Fos protein, Immunoreactivity, Serotonin, Tryptophan.

\section{INTRODUCTION}

Serotonin is a monoamine that functions as a neurotransmitter and neuromodulator. Serotonin-producing neurons, located in the raphe nuclei, show widespread projections to different brain regions, and are involved in several neurobiological processes, i.e. food intake, sexual and social behavior, cognition and decision making, locomotor activity,

Correspondence to: Isabel Cristina Céspedes

E-mail: isabel.cespedes@unifesp.br aggression, circadian rhythms, and neuroendocrine function, among others (Lam et al. 2010, Wurtman and Wurtman 1986, Maniam and Morris 2012, Kiser et al. 2012, Homberg 2012, Clissold et al. 2013, Jacobs and Fornal 1999).

Altered serotonin activity has also been recognized as an important factor in pathological conditions, such as anxiety and mood disorders (Deakin and Graeff 1991, Hale et al. 2012). In fact, first option pharmacological treatment for these psychopathologies are antidepressants, which act through 
facilitation of monoamine neurotransmission, in particular of serotonin, as is the case of drugs such as fluoxetine and sertraline, which selectively inhibit serotonin reuptake (Den Boer et al. 2000, Bandelow et al. 2007, 2012, Stein and Lopez 2011, Andrisano et al. 2013).

Tryptophan is the only precursor of serotonin (Fernstrom 1983) and mediates serotonergic activity in the brain. The consumption of tryptophan can increase the concentration of serotonin in the Central Nervous System and change the metabolism and activity of the serotonergic system (Lieberman et al. 1985). Tryptophan is converted to serotonin through a biochemical pathway composed of two enzymes: tryptophan hydroxylase and amino acid decarboxylase. Tryptophan hydroxylase is the rate-limiting enzyme that converts tryptophan into serotonin and it is not normally saturated with tryptophan. It has been shown that the administration of $3 \mathrm{~g}$ of tryptophan increases up to twofold the synthesis of serotonin (Young and Gauthier 1981, Young 1996). Previous studies have also shown that this increase in serotonin levels significantly modulates mood and cognition (Attenburrow et al. 2003, Cunliffe et al. 1998, Marsh et al. 2002, Markus et al. 2008, Richard et al. 2009, Silber and Schmitt 2010). Additionally, it has also been shown that tryptophan depletion increases anxiety and panic, both in healthy volunteers (Klaassen et al. 1998) and in panic disorder patients (Miller et al. 2000).

Nevertheless, the neurobiological alterations that follow these changes have not yet been fully investigated. It has been shown, however, that tryptophan overloading, apart from increasing serotonin release (as measured by in vivo microdialysis), decreases the number of Fosimmunoreactive cells activated by light in the supraquiasmatic nucleus of male Syrian hamsters (Glass et al. 1995). This alteration seems to be related to changes in the sleep/wake cycle regulated by serotonin neurotransmission.
Taking the above into account, the aim of this study was to investigate the effect of a tryptophanenriched diet on Fos protein immunoreativity (Fos-ir) in the dorsal and median raphe and in brain areas innervated by serotonin neurons and related to cognition, mood and anxiety. As formerly noted, the product of the immediate-early gene c-fos is expressed throughout the brain in response to a variety of tasks, thus making it a powerful instrument to study intracellular responses of neurons to different stimuli (Hale et al. 2006).

\section{MATERIALS AND METHODS}

\section{SUBJECTS}

Sixteen male Wistar rats in the Centre for Development of Experimental Models for Medicine and Biology of the Federal University of São Paulo were kept under controlled environmental conditions $\left(21 \pm 1^{\circ} \mathrm{C}\right.$, light / dark cycle of $12 \mathrm{~h}$, free access to water and feed) in the Animal Facility of the Department of Biosciences - Federal University of São Paulo-Santos. The study was approved by the Ethical Committee for Animal Research of the Federal University of São Paulo (number 0247/12) and was performed in compliance with the recommendations of the Brazilian Society of Neuroscience and Behavior, which are based on the conditions stated in the "Guide for the Care and Use of Laboratory Animals" (Institute of Laboratory Animal Resources on Life Sciences, National Research Council, 1996).

\section{DESCRIPTION OF THE DIET}

The animals were distributed into two groups that received either a standard chow diet (Nuvilab ${ }^{\circledR}$, Brazil) or a tryptophan-enriched diet (Rhoster ${ }^{\circledR}$, Brazil) for thirty days. The monitoring of food intake was performed every two days and the animals were weighed weekly. The composition of the tryptophan-enriched diet is described in Table I. 
TABLE I

Composition of standard and tryptophan-enriched diets.

\begin{tabular}{lr}
\hline \multicolumn{1}{c}{ Standard chow diet } & g/kg \\
\hline Corn starch & 579.5 \\
\hline Casein & 200.0 \\
\hline Saccharose & 100.0 \\
\hline Mix Mineral AIN-93G & 35.0 \\
\hline Mix Vitamin AIN-93 & 10.0 \\
\hline L-Cystine & 3.0 \\
\hline Choline & 2.5 \\
\hline Butylated hydroxytoluene & 0.014 \\
\hline Sunflower oil & 70.0 \\
\hline \multicolumn{1}{c}{ Tryptophan-enriched diet (0.5\%) } \\
\hline Saccharose & 679.9 \\
\hline Casein & 200.0 \\
\hline Gelatin & 12.0 \\
\hline Refined peanut oil & 50.0 \\
\hline Mix Mineral AIN-93G & 40.0 \\
\hline Mix Vitamin AIN-93 & 6.0 \\
\hline Choline & 4.0 \\
\hline L-Methionine & 3.0 \\
\hline L-Alanine & 0.022 \\
\hline L-Tryptophan & 5.0 \\
\hline Vitamin A (Acetate 500.000 UI/g) & 0.02 \\
\hline Vitamin D3 (40.000.000 UI/g) & 0.00002 \\
\hline Vitamin E (500 UI/g) & 0.001 \\
\hline
\end{tabular}

\section{FOS PROTEIN IMMUNOREACTIVITY (FOS-IR)}

Neurons respond to extracellular stimuli through the expression of certain genes, called immediate early genes. Fos transcription from the $c$-fos gene is among the first protein transcripts to appear. The rapid accumulation of this protein, evidenced by immunohistochemical methods, offers the possibility of detecting the level of neuronal activity. Thus, the study of immunoreactivity to Fos protein was used in the present study as a marker of neuronal activity (Bullitt 1990, Titze-de-Almeida et al. 1994, Céspedes et al. 2010).

On the morning of the 31 st day of treatment, the animals were weighed and then anesthetized with ketamine/xylazine 2:1 (1 ml/kg) and perfused with $\approx 100 \mathrm{ml}$ of $0.9 \%$ saline for approximately 1 min, followed by $500-700 \mathrm{ml}$ of $4 \%$ formaldehyde (from paraformaldehyde heated to $60-65^{\circ} \mathrm{C}$ ) and $\mathrm{H}_{2} \mathrm{O}$ at $4{ }^{\circ} \mathrm{C}$, pH 9.5, for approximately $25 \mathrm{~min}$. The brains were post-fixed for $1 \mathrm{~h}$ in the same fixative solution, and then stored in a solution containing $20 \%$ sucrose for cryoprotection at $4{ }^{\circ} \mathrm{C}$. Regularly spaced series $(5 \times 1$-in- 5$)$ of $30 \mu \mathrm{m}$-thick frozen sections were cut in the coronal plane, collected in ethylene glycol-based cryoprotectant solution and stored at $-20^{\circ} \mathrm{C}$ for later determination of $\mathrm{Fos}$ ir. Fos-ir cells were identified using a polyclonal anti-serum raised in rabbits against synthetic human Fos (anti-Fos - 1:20,000; Oncogene, Cambridge, MA, USA). Immunohistochemistry was performed using a conventional avidinbiotin immunoperoxidase protocol ( $\mathrm{Hsu}$ and Raine 1981) and Vectastain Elite reagents (Vector Laboratories ${ }^{\circledR}$, Burlingame, CA, USA). Tissue was pretreated with hydrogen peroxide $\left(0.3 \%\right.$; Sigma ${ }^{\circledR}$, St. Louis, MO, USA) before addition of the primary antibody to quench endogenous peroxidase activity in the tissue. The reaction with diaminobenzidine (DAB) $\left(0.05 \%\right.$; Sigma $\left.{ }^{\circledR}\right)$ was amplified using nickel ammonium sulfate. The sections were then mounted on gelatin-coated slides, allowed to dry for approximately 18 hours and counterstained with $0.25 \%$ thionin for identification of the nervous tissue cytoarchitecture. We quantified Fos-ir cells in sections, under bright-field illumination using the Image-Pro Plus software (Media Cybernetics ${ }^{\circledR}$, Silver Spring, MD, USA), and having as reference the following AP coordinates (Paxinos and Watson 2007): prefrontal cortex (PFC) (bregma +2.76 $\mathrm{mm})$, medial, lateral and basolateral amygdala (bregma $-2.76 \mathrm{~mm}$ ), dentate gyrus and CA1, 2 and 3 regions of the hippocampus (bregma $-2.76 \mathrm{~mm}$ ), ventromedial hypothalamus (VMH) (bregma -2.92 $\mathrm{mm}$ ), lateral hypothalamus (LH) (bregma -1.80 $\mathrm{mm}$ ), paraventricular hypothalamus $(\mathrm{Pa})$ (bregma $-1,92 \mathrm{~mm}$ ) and arcuate nucleus (Arc) (bregma -1.80 $\mathrm{mm}$ ) of the hypothalamus, nucleus accumbens (Acb) (bregma $+0.70 \mathrm{~mm}$ ), dorsomedial (DMPAG) and dorsolateral periaqueductal grey (DLPAG) (bregma $-6.36 \mathrm{~mm}$ ) and dorsal (DR) and median raphe (MnR) (bregma $-7.44 \mathrm{~mm}$ ) nuclei. The experimenter performing both the staining and the analysis was blind to the experimental conditions. 


\section{STATISTICAL ANALYSIS}

The weight of the animals was analyzed by repeated measures ANOVA, with treatment as the independent and the weighing sessions as the dependent factor. Fos-ir data was analyzed by unpaired Student T-test. A value of $\mathrm{P}<0.05$ was considered significant.

\section{RESULTS}

Table II shows the weight of the animals during the treatment period. Repeated measures ANOVA showed a significant effect of the weighing sessions $(\mathrm{F}(4,56)=245.8 ; \mathrm{P}<0.001)$, but not a significant effect of treatment $(\mathrm{F}(1,14)=0.010 ; \mathrm{P}=0.922)$ or of treatment by weighing session interaction $(\mathrm{F}(4,56)=0.176 ; \mathrm{P}=0.950)$.
Table III shows Fos-ir in the different brain regions related to cognition, mood and behavior, innervated by serotonin. Unpaired Student T-test showed that the group that received the diet enriched with tryptophan showed a significantly greater number of activated cells when compared to the group that received the control diet in the following regions: PFC $(\mathrm{T}(7.03)=-2.49 ; P=$ 0.042 ) (figure 1a), Acb $(\mathrm{T}(3.30)=-3.15 ; P=$ $0.045)$ (figure $1 \mathrm{~b}), \operatorname{Arc}(\mathrm{T}(4.83)=-3.41 ; P=0.020)$ (figure 1c), $\mathrm{Pa}(\mathrm{T}(5.07)=-2.87 ; P=0.035)$ (figure $1 \mathrm{~d}), \mathrm{VMH}(\mathrm{T}(11)=2.70 ; P=0.021)($ figure $1 \mathrm{e})$, DLPAG $(\mathrm{T}(7.36)=-5.09 ; P=0.001)$ (figure $2 \mathrm{a})$, DMPAG $(\mathrm{T}(7.00)=-3.47 ; P=0.010)$ (figure $2 \mathrm{~b}$ ), $\mathrm{DR}(\mathrm{T}(3.36)=-2.92 ; P=0.05)$ (figure $2 \mathrm{c}$ ), and $\operatorname{MnR}(\mathrm{T}(7.40)=-3.42 ; P=0.010)$ (figure $2 \mathrm{~d}$ ).

TABLE II

Weight (mean \pm SEM) of animals fed with a standard chow diet or a tryptophan-enriched diet.

\begin{tabular}{lccccc}
\hline Treatment & Day 1 & Day 8 & Day 15 & Day 22 & Day 29 \\
\hline Standard diet & $286.25 \pm 6.92$ & $323.38 \pm 7.25$ & $351.75 \pm 8.35$ & $372.88 \pm 8.05$ & $388.50 \pm 12.29$ \\
\hline Tryptophan-enriched diet & $283.13 \pm 6.24$ & $321.88 \pm 6.03$ & $350.50 \pm 8.42$ & $370.50 \pm 9.19$ & $391.13 \pm 11.59$ \\
\hline
\end{tabular}

TABLE III

Fos-immunoreactivity (mean $\pm \mathrm{SEM}$ ) in different brain areas of animals treated with standard or tryptophan-enriched diets for 30 days.

\begin{tabular}{lcc}
\hline Areas & Standard Diet & Tryptophan-enriched diet \\
\hline Prefrontal cortex & $23.0 \pm 7.5$ & $439.4 \pm 167.2^{*}$ \\
\hline Accumbens & $72.6 \pm 20.8$ & $372.3 \pm 92.7^{*}$ \\
\hline Dentate Gyrus & $21.9 \pm 4.7$ & $15.3 \pm 2.8$ \\
\hline CA1 & $2.3 \pm 0.8$ & $17.5 \pm 8.7$ \\
\hline CA2 & $17.5 \pm 8.7$ & $12.8 \pm 6.3$ \\
\hline CA3 & $2.3 \pm 0.8$ & $4.6 \pm 59.1$ \\
\hline Basolateral amygdala & $27.6 \pm 2.2$ & $92.8 \pm 59.2$ \\
\hline Lateral amygdala & $14.3 \pm 8.1$ & $30.6 \pm 11.2$ \\
\hline Medial amygdala & $38.3 \pm 11.4$ & $56.8 \pm 20.9$ \\
\hline Lateral hypothalamus & $62.4 \pm 10.8$ & $58.8 \pm 17.7$ \\
\hline Ventromedial hypothalamus & $141.1 \pm 13.5$ & $67.2 \pm 25.2^{*}$ \\
\hline Paraventricular hypothalamus & $43.0 \pm 7.8$ & $106.4 \pm 20.7^{*}$ \\
\hline Arcuate nucleus & $23.3 \pm 4.6$ & $74.0 \pm 14.1 *$ \\
\hline Dorsomedial periaqueductal grey & $1.6 \pm 0.6$ & $247.5 \pm 70.9^{*}$ \\
\hline Dorsolateral periaqueductal grey & $6.5 \pm 3.8$ & $128.3 \pm 23.6^{*}$ \\
\hline Median raphe & $84.0 \pm 16.1$ & $253.6 \pm 46.9^{*}$ \\
\hline Dorsal raphe & $35.0 \pm 8.6$ & $141.0 \pm 35.3^{*}$
\end{tabular}

CA: Cornus Ammon. $\mathrm{P}<0.05$, unpaired Student T-test. 
CONTROL
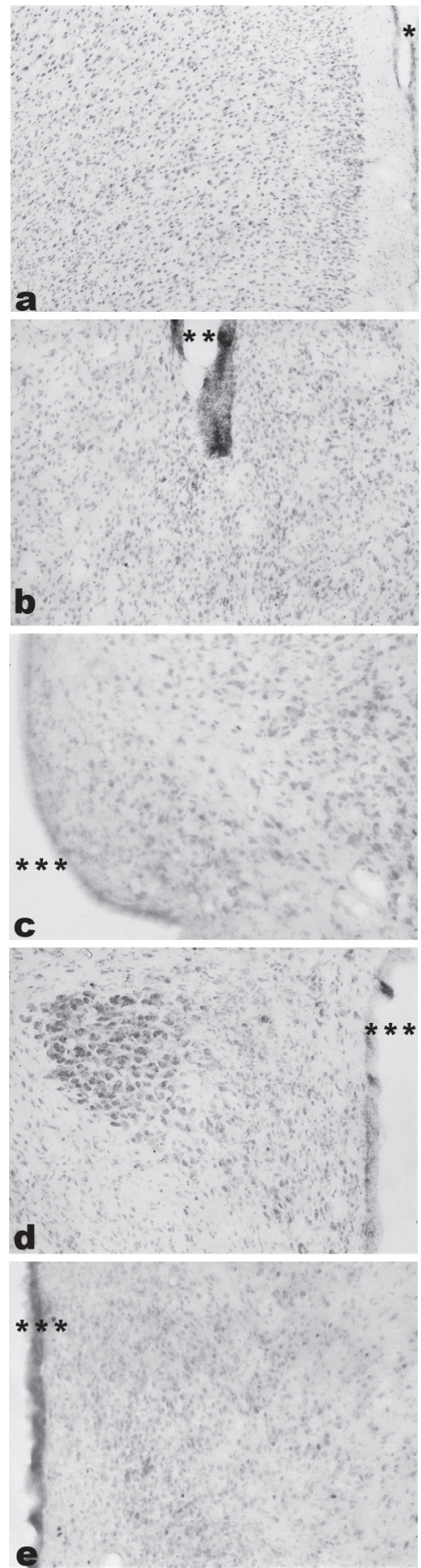

TRYPTOPHAN
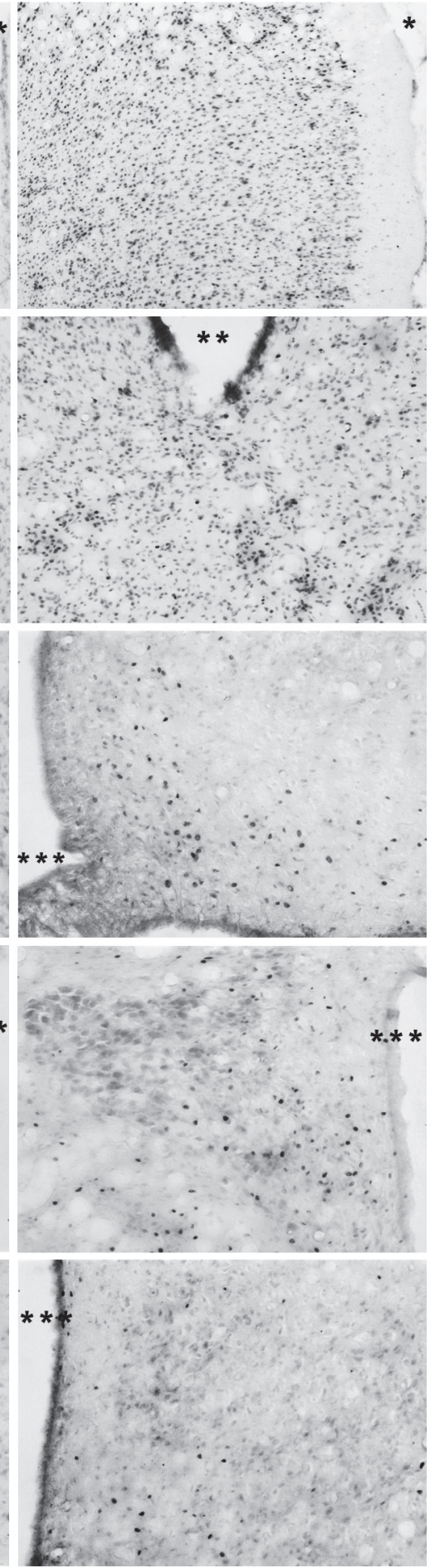

Figure 1 - Photomicrographs of Fos immunoreactive cells (dark spots) in coronal sections through brain regions with significant increases in Fos immunoreactivity in the animals that received the diet enriched with tryptophan. (a): prefrontal cortex; (b): nucleus accumbens; (c) arcuate nucleus; (d): paraventricular hypothalamus; (e) ventromedial hypothalamus. A, B: Magnification, $\times 100$; C, D, E: Magnification, $\times 200$. $(*)$ longitudinal fissure of the brain; $(* *)$ lateral ventricle; $(* * *)$ third ventricle. 


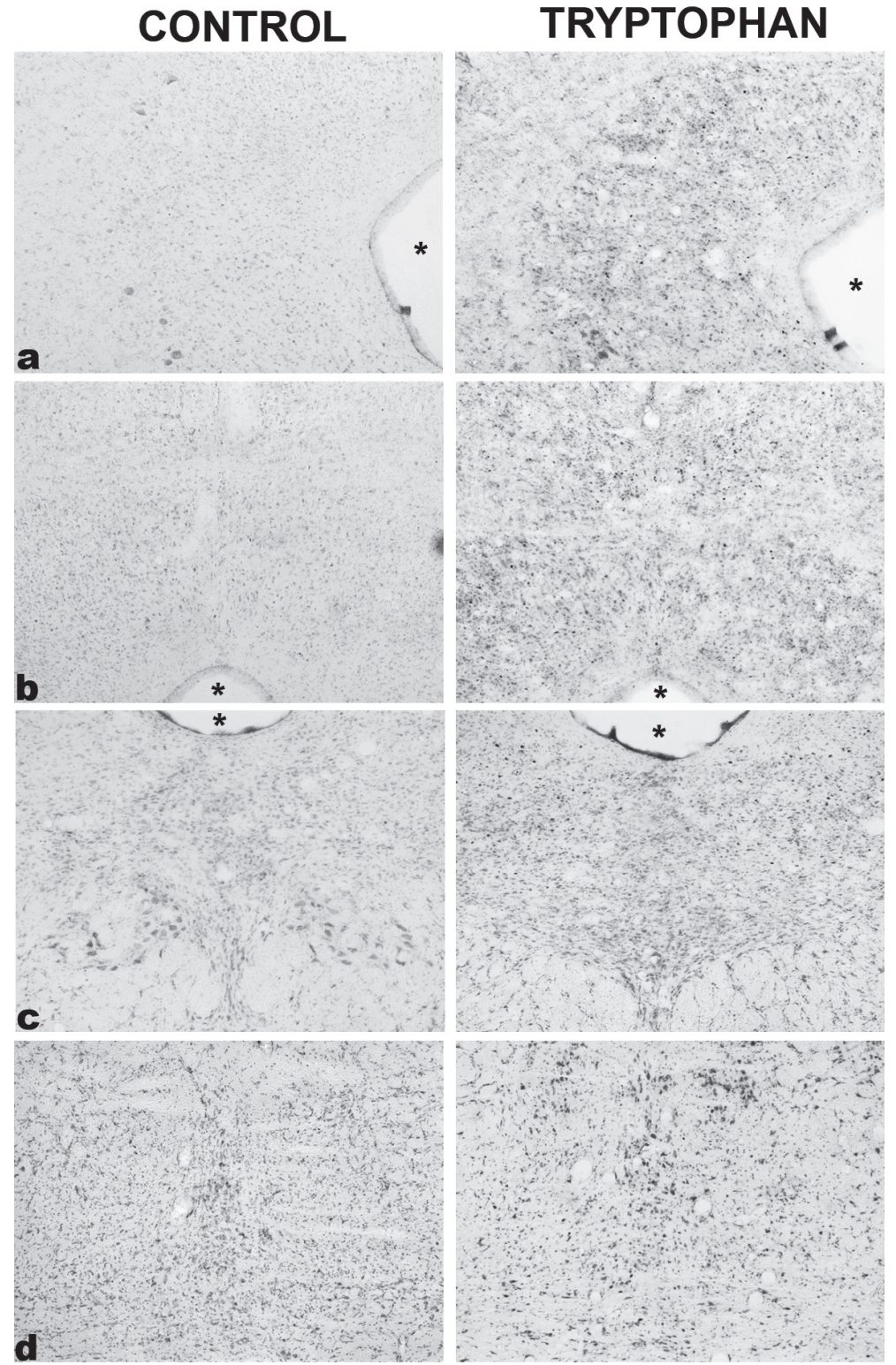

Figure 2 - Photomicrographs of Fos immunoreactive cells (dark spots) in coronal sections through brain regions with significant increases in Fos immunoreactivity in the animals that received the diet enriched with tryptophan. (a): dorsolateral periaqueductal grey; (b): dorsomedial periaqueductal grey; (c) dorsal raphe; (d): median raphe. Magnification, $\times 100$. $(*)$ cerebral aqueduct.

No significant differences were found between the two groups in the other regions analyzed $(P>$ $0.05)$.

\section{DISCUSSION}

The results of the present study showed that although treatment with a tryptophan-enriched diet did not interfere with the weight of the animals, it significantly increased Fos-ir in the PFC, Acb, Pa, Arc and VMH, DLPAG and DMPAG and DR and $\mathrm{MnR}$.

The PFC is densely interconnected with numerous cortical and subcortical structures, such as the thalamus and the brainstem (Puig and 
Gulledge 2011, Miller and Cohen 2001, Fuster 1997, 2001). Previous evidence supports the idea that the PFC is related to emotional control (MyersSchulz and Koenigs 2012), regulating executive tasks of higher order, such as learning, memory, categorization, inhibitory control and executive flexibility, among others (Puig and Gulledge 2011). Also the PFC seems to play a pivotal role in the regulation of mood and anxiety-related responses (Drevets et al. 2008, Fredericks et al. 2006, Milad and Rauch 2006, Price and Drevets 2010). Serotonergic neurons of the DR and MnR send axons to different subregions of the PFC such as the cingulate, prelimbic and infralimbic cortices (Groenewegen and Uylings 2000). Thus, serotonin seems to play an important role in the modulation of PFC activity (Puig and Gulledge 2011, Puig et al. 2005).

According to in vitro studies performed with rat brain slices, PFC pyramidal neurons co-express serotonin $1 \mathrm{~A}$ and $2 \mathrm{~A}$ receptors (Puig and Gulledge 2011). It is thus possible that the increases in Fosir in the PFC caused by tryptophan overload are related to the activation of serotonin receptors in PFC neurons. This may be one of the mechanisms by which the supplementation of tryptophan in clinical trials alters mood, cognition and behavior (Puig and Gulledge 2011, Miller and Cohen 2001, Fuster 1997, 2001).

It is also well known that the PFC sends important inhibitory projections to the amygdala, reducing fear responses and amygdala outputs (Akirav and Maroun 2007). It has been shown, for instance, that stimulation of the medial PFC decreases the firing of central amygdala cells that respond to conditioned stimuli when animals are recalling extinction of a fear conditioned task (Milad and Quirk 2002). Additionally, PFC lesions seem to increase the resistance to fear extinction. Taking this evidence into account, it has been proposed that the connections between the PFC and the amygdala allow the modification of emotional behavior in the face of environmental changes (Akirav and Maroun 2007). The malfunctioning of this inhibitory neurocircuitry could therefore underlie one's inability to regulate emotions, i.e. fear/anxiety. The activation of the PFC observed in the present study might also explain why none of the amygdala nuclei investigated (the medial, the lateral and the basolateral amygdala) showed increased Fos-ir. Another possible explanation, however, for the absence of increases in Fos-ir in regions related to the regulation of mood and stress/anxiety (such as the amygdala and the hippocampus) might be related to the fact that in the present study the animals were not confronted with aversive stimuli or any other kind of behavioral challenge.

The Acb also receives projections from the PFC (Del Arco and Mora 2008). This circuitry seems to regulate in particular the release of dopamine in this brain area, and has been proposed to function as a pathway through which anhedonia, a core symptom of depression, is installed (Heller et al. 2009). Previous studies have shown that depressed individuals or those with traitlike anhedonia display a lack of increase in Acb activity when presented with pleasurable stimuli (Epstein et al. 2006). Also, a magnetic resonance imaging study performed with depressed and healthy volunteers (Heller et al. 2009) showed that: 1) patients presented an inability to sustain Acb activity when asked to up-regulate positive effects; 2) deficits in sustaining activity in the Acb were specific to positive emotions (and not related to negative stimuli); 3) patients who failed to sustain Acb activity reported less positive emotions (in other words, anhedonia); 4) and, importantly, difficulties in sustaining Acb were related to reduced PFC connectivity. In this sense, it has been suggested that PFC neuronal activity could be associated with both anxiety and depression, depending on the neurocircuitry analyzed. In fact, a recent optogenetics study (Vialou et al. 
2014) showed that stimulation of corticoamygdala projections blocked the anxiogenic-like effects of cholecystokinin (CCK) administration into the PFC of mice, without altering depression-related social defeat behaviors. Conversely, stimulation of PFC-Acb projections reversed CCK-induced social avoidance and sucrose preference deficits, without altering the anxiogenic-like effects induced by CCK administration. Together, these results seem to suggest that activation of the PFC could be related to a decrease in anxiety (by diminishing amygdalar activity) and to a decrease in depression-related symptoms (by increasing Acb activity).

Another region that showed increases in Fosir in the present study was the periaqueductal grey (PAG). This brainstem structure is divided along its rostro-caudal axis into four columns: the DMPAG, the DLPAG, the lateral and the ventrolateral columns (Moreira and Guimarães 2005). The dorsal columns of the PAG are particularly involved in fear/panicrelated behaviors. In fact, it has been proposed that serotonin plays a panicolytic-like role by activating serotonin $1 \mathrm{~A}$ and $2 \mathrm{~A}$ receptors in the dorsal $\mathrm{PAG}$ (Graeff 2002). It is thus interesting that in the present study tryptophan overload significantly increased the number of neurons activated in the DMPAG and DLPAG columns. Since it has been previously shown that tryptophan depletion increases anxiety and panic, both in volunteers (Klassen et al. 1998) and in panic disorder patients (Miller et al. 2000), it is possible that tryptophan overload leads to a decrease in panic-related symptoms by activating serotonin neurons in the dorsal PAG. Nevertheless, this proposition needs to be better investigated.

The DR and the MnR are the main raphe nuclei that send serotonergic projections to the regions described above (Azmitia 2001). Around two-thirds of all neurons in the rat DR are serotonergic (Molliver 1987, Jacobs and Azmitia 1992). In the present study, both the DR and the MnR also showed increases in Fos-ir after tryptophan overload. This effect is probably due to an increase in serotonin synthesis. A previous study showed that $50 \mathrm{mg}$ /day of tryptophan led to increases in the levels of 5-hydroxyindoleacetic acid, a metabolite of serotonin, in the rat DR (Hayashi et al. 2006). According to a hypothesis proposed by Deakin and Graeff (1991) the medial forebrain bundle that originates in the DR facilitates avoidance behaviors that occur in response to potential or distal threat, by releasing serotonin in forebrain structures, an anxiogenic-like effect. On the other hand, and as previously mentioned, by acting in the dorsal PAG, serotonin from the DR would inhibit panic-related reactions. The authors also suggest that the pathway connecting the MnR to the hippocampus promotes resistance to chronic stress, and in this sense would be implicated in mood modulation, and in particular in the pathophysiology of depression (Graeff et al. 1996).

On the other hand, it is also important to point out that neurons within the regions analyzed are not exclusively involved in cognition and mood/ anxiety, but also in many other physiological processes such as thermo- and pain-regulation, cardiorespiratory function, locomotor activity and food intake (Jacobs and Fornal 1993, Rossi et al. 1994, Behbehani 1995, Simpson et al. 2008, Hale et al. 2012). Therefore, increases in Fos-ir may be related to changes in other regulatory mechanisms, not necessarily related to the therapeutic effects of tryptophan overload in cognition, mood or anxiety. For instance, apart from its important role in stress regulation (Fekete and Lechan 2014), the $\mathrm{Pa}$ is also part of a neuronal circuitry that regulates food intake. The best-characterized neurochemical pathways related to energy consumption and food intake are the orexigenic neuropeptide Y/ Agouti-related protein and the anorexigenic proopiomelanocortin/cocaine- and amphetaminerelated transcript neurons in the Arc (Wang et al. 2015), which also showed increases in Fos-ir in the present study. These neurons project from the Arc to other key hypothalamic nuclei, such as the $\mathrm{Pa}$ and the VMH (Kotagale et al. 2014). 
There is an intense projection of serotonergic fibers from the raphe nuclei (activated by tryptophan supplementation) to the Arc and Pa. There is also significant expression of serotonin $2 \mathrm{~A}$ receptors in the $\mathrm{Pa}$ and serotonin $1 \mathrm{~B}$ and $2 \mathrm{C}$ receptors in the Arc (Gundlah et al. 1999). Activation of serotonin $2 \mathrm{C}$ receptors stimulates ARC pro-opiomelanocortin neurons that express the precursor peptide $\alpha$-melanocortin stimulating hormone (thus reducing food intake). On the other hand, activation of serotonin $1 \mathrm{~B}$ receptors in the Arc inhibits neuronal activity of neurons that express neuropeptide Y/Agouti-related protein (increasing food intake) and reduces post-synaptic inhibitory signals on neurons expressing the anorexigenic pro-opiomelanocortin (Heisler et al. 2002, 2006). This control of the melanocortin system may represent an important mechanism by which serotonin reduces food intake. Such a mechanism may be evidenced by the increased activation of these nuclei, suggesting that treatment with tryptophan can have a functional impact either by the increased production of serotonin or by the stimulation of serotonergic receptors in different brain regions. Pharmacological experiments also show that serotonin stimulates neurons in the VMH to promote satiety (Jia et al. 2010). The VMH receives projections from Arc neurons that express the neuropeptide Y/Agouti-related protein and the $\alpha$-melanocortin stimulating hormone. Serotonin modulates this process through its release in the core region of the Arc. Therefore, the activation of tryptophan in the VMH can also be attributed to an increased production and release of serotonin promoted by the ingestion of tryptophan.

In summary, our results show, to our knowledge for the first time, the effects of tryptophan overload in the activation of different brain areas. The increases in neuronal activity promoted by tryptophan intake in supplemented animals highlight the important modulatory role that nutrients can exert on the Central Nervous System and emphasize the need for further studies to assess the effects of diet compositions on specific brain circuits.

\section{ACKNOWLEDGMENTS}

This study was partially supported by Fundação de Amparo à Pesquisa do Estado de São Paulo (FAPESP). LCAS received an undergraduate research grant from FAPESP.

\section{REFERENCES}

AKIRAV I AND MAROUN M. 2007. The role of the medial prefrontal cortex-amygdala circuit in stress effects on the extinction of fear. Neural Plast 2007: 30873.

ANDRISANO C, CHIESA A AND SERRETTI A. 2013. Newer antidepressants and panic disorder: a meta-analysis. Int Clin Psychopharmacol 28: 33-45.

ATTENBURROW MJ, WILLIAMS C, ODONTIADIS J, POWELL J, VAN DE OUDERAA F, WILLIAMS M AND COWEN PJ. 2003. The effect of a nutritional source of tryptophan on dieting-induced changes in brain 5-HT function. Psychol Med 33: 1381-1386.

AZMITIA EC. 2001. Modern views on an ancient chemical: Serotonin effects on cells proliferation, maturation, and apoptosis. Brain Res Bull 56: 413-424.

BANDELOW B et al. 2012. Guidelines for the pharmacological treatment of anxiety disorders, obsessive-compulsive disorder and posttraumatic stress disorder in primary care. Int J Psychiatry Clin Pract 16:77-84.

BANDELOW B, ANDERSEN HF AND DOLBERG OT. 2007. Escitalopram in the treatment of anxiety symptoms associated with depression. Depress Anxiety 24: 53-61.

BEHBEHANI MM. 1995. Functional characteristics of the midbrain periaqueductal gray. Prog Neurobiol 46: 575605.

BULLITT E. 1990. Expression of c-fos-like protein as a marker for neuronal activity following noxious stimulation in the rat. J Comp Neurol 296: 517-530.

CESPEDES IC, DE OLIVEIRA AR, DA SILVA JM, DA SILVA AV, SITA LV AND BITTENCOURT JC. 2010. mRNA expression of corticotropin-releasing factor and urocortin 1 after restraint and foot shock together with alprazolam administration. Peptides 31(12): 2200-2208.

CLISSOLD KA, CHOI E AND PRATT WE. 2013. Serotonin $1 \mathrm{~A}, 1 \mathrm{~B}$, and 7 receptors of the rat medial nucleus accumbens differentially regulate feeding, water intake, and locomotor activity. Pharmacol Biochem Behav 112: 96-103.

CUNLIFFE A, OBEID OA AND POWELL-TUCK J. 1998. A placebo controlled investigation of the effects of tryptophan 
or placebo on subjective and objective measures of fatigue. Eur J Clin Nutr 52: 425-430.

DEAKIN JF AND GRAEFF FG. 1991. 5-HT and mechanisms of defence. J Psychopharmacol 5: 305-315.

DEAKIN JFW AND GRAEFF FG. 1991. 5-HT and mechanisms of defence. J Psychopharmacol 5: 339-341.

DEL ARCO AAND MORA F. 2008. Prefrontal cortex-nucleus accumbens interaction: in vivo modulation by dopamine and glutamate in the prefrontal cortex. Pharmacol Biochem Behav 90: 226-235.

DEN BOER JA, BOSKER FJ AND SLAAP BR. 2000. Serotonergic drugs in the treatment of depressive and anxiety disorders. Hum Psychopharmacol 15: 315-336.

DREVETS WC, PRICE JL AND FUREY ML. 2008. Brain structural and functional abnormalities in mood disorders: implications for neurocircuitry models of depression. Brain Struct Funct 213: 93-118.

EPSTEIN J et al. 2006. Lack of ventral striatal response to positive stimuli in depressed versus normal subjects. Am J Psychiatry 163: 1784-1790.

FEKETE C AND LECHAN RM. 2014. Central regulation of hypothalamic-pituitary-thyroid axis under physiological and pathophysiological conditions. Endocr Rev 35: 159194.

FERNSTROM JD. 1983. Role of precursor availability in control of monoamine biosynthesis in brain. Physiol Rev 63: 484-546.

FREDERICKS CA, KALMAR JH AND BLUMBERG HP. 2006. The role of the ventral prefrontal cortex in mood disorders. In: ZALD DH AND RAUCH SL (Eds), The Orbitofrontal Cortex. New York: Oxford University Press, p. $544-577$.

FUSTER J. 2001. The prefrontal cortex--an update: time is of the essence. Neuron 30: 319-333.

FUSTER JM. 1997. The Prefrontal Cortex- Anatomy, physiology and neuropsychology of the frontal lobe. Philadelphia-New York: Linpicott-Raven.

GLASS JD, SELIM M, SRKALOVIC G AND REA MA. 1995. Tryptophan loading modulates light-induced responses in the mammalian circadian system. J Biol Rhythms 10: 8090.

GRAEFF FG. 2002. On serotonin and experimental anxiety. Psychopharmacology 163: 467-476.

GRAEFF FG, GUIMARÃES FS, DE ANDRADE TG AND DEAKIN JF. 1996. Role of 5-HT in stress, anxiety, and depression. Pharmacol Biochem Behav 54: 129-141.

GROENEWEGEN HJ AND UYLINGS HB. 2000. The prefrontal cortex and the integration of sensory, limbic and autonomic information. Prog Brain Res 126: 3-28

GUNDLAH C, PECINS-THOMPSON M, SCHUTZER WE AND BETHEA CL. 1999. Ovarian steroid effects on serotonin $1 \mathrm{~A}, 2 \mathrm{~A}$ and $2 \mathrm{C}$ receptor mRNA in macaque hypothalamus. Mol Brain Res 63: 325-339.
HALE MW, BOUWKNECHT JA, SPIGA F, SHEKHAR A AND LOWRY CA. 2006. Exposure to high- and low-light conditions in an open-field test of anxiety increases c-Fos expression in specific subdivisions of the rat basolateral amygdaloid complex. Brain Res Bull 71: 174-182.

HALE MW, SHEKHAR A AND LOWRY CA. 2012. Stress-related serotonergic systems: implications for symptomatology of anxiety and affective disorders. Cell Mol Neurobiol 32: 695-708.

HAYASHI M, SHIRAI Y, BANDOH T, IWAMASA K, SHINDOME N AND HOSHI K. 2006. Alteration of 5-HIAA levels in frontal cortex and dorsal raphe nucleus in rats treated with combined administration of tryptophan and ethanol. J Toxicol Sci 31: 235-246.

HEISLER LK et al. 2002. Activation of central melanocortin pathways by fenfluramine. Science 297: 609-611.

HEISLER LK et al. 2006. Serotonin reciprocally regulates melanocortin neurons to modulate food intake. Neuron 51: 239-249.

HELLER AS, JOHNSTONE T, SHACKMAN AJ, LIGHT SN, PETERSON MJ, KOLDEN GG, KALIN NH AND DAVIDSON RJ. 2009. Reduced capacity to sustain positive emotion in major depression reflects diminished maintenance of fronto-striatal brain activation. Proc Natl Acad Sci U S A 106: 22445-22450.

HOMBERG JR. 2012. Serotonin and decision making processes. Neurosci Biobehav Rev 36: 218-236.

HSU SM AND RAINE L. 1981. Protein A, avidin, and biotin in immunohistochemistry. J Histochem Cytochem 29: 1349-1353.

JACOBS BLAND AZMITIA EC. 1992. Structure and function of the brain serotonin system. Physiol Rev 72: 165-229.

JACOBS BL AND FORNAL CA. 1993. 5-HT and motor control: a hypothesis. Trends Neurosci 16: 346-352.

JACOBS BL AND FORNAL CA. 1999. Activity of serotonergic neurons in behaving animals. Neuropsychopharmacology 21: S9-15

JIA Y, EL-HADDAD M, GENDY A, NGUYEN T AND ROSS MG. 2010. Serotonin-induced region-specific responses of the arcuate and ventromedial hypothalamic nuclei. Int J Neurosci 120: 386-395.

KISER D, STEEMER SB, BRANCHI I AND HOMBERG JR. 2012. The reciprocal interaction between serotonin and social behavior. Neurosci Biobehav Rev 36: 786-798.

KLAASSEN T, KLUMPERBEEK J, DEUTZ NE, VAN PRAAG HM AND GRIEZ E. 1998. Effects of tryptophan depletion on anxiety and on panic provoked by carbon dioxide challenge. Psychiatry Res 77: 167-174.

KOTAGALE NR, UPADHYA M, HADOLE PN, KOKARE DM AND TAKSANDE BG. 2014. Involvement of hypothalamic neuropeptide $\mathrm{Y}$ in pentazocine induced suppression of food intake in rats. Neuropeptides 48: 133141. 
LAM DD, GARFIELD AS, MARSTON OJ, SHAW J AND HEISLER LK. 2010. Brain serotonin system in the coordination of food intake and body weight. Pharmacol Biochem Behav 97: 84-91.

LIEBERMAN HR, CORKIN S, SPRING BJ, WURTMAN RJ AND GROWDON JH. 1985. The effects of dietary neurotransmitter precursors on human behavior. Am J Clin Nutr 42: 366-370.

MANIAM J AND MORRIS MJ. 2012. The link between stress and feeding behavior. Neuropharmacology 63: 97-110.

MARKUS CR, FIRK C, GERHARDT C, KLOEK J AND SMOLDERS GF. 2008. Effect of different tryptophan sources on amino acids availability to the brain and mood in healthy volunteers. Psychopharmacology (Berl) 201: 107-114.

MARSH DM, DOUGHERTY DM, MOELLER FG, SWANN AC AND SPIGA R. 2002. Laboratory-measured aggressive behavior of women: acute tryptophan depletion and augmentation. Neuropsychopharmacology 26: 660671.

MILAD MR AND QUIRK GJ. 2002. Neurons in medial prefrontal cortex signal memory for fear extinction. Nature 420: 70-74.

MILAD MR AND RAUCH SL. 2006. The orbitofrontal cortex and anxiety disorders. In: ZALD DH AND RAUCH SL (Eds), The Orbitofrontal Cortex. New York: Oxford University Press, p. 523-543.

MILLER EK AND COHEN JD. 2001. An integrative theory of prefrontal cortex function. Annu Rev Neurosci 24:167202.

MILLER HE, DEAKIN JF AND ANDERSON IM. 2000. Effect of acute tryptophan depletion on $\mathrm{CO} 2$-induced anxiety in patients with panic disorder and normal volunteers. Br J Psychiatry 176: 182-188.

MOLLIVER ME. 1987. Serotonergic neuronal systems: what their anatomic organization tells us about function. J Clin Psychopharmacol 7: 3S-23S.

MOREIRA FA AND GUIMARÃES FS. 2005. Role of serotonin receptors in panic-like behavior induced by nitric oxide in the rat dorsolateral periaqueductal gray: Effects of chronic clomipramine treatment. Life Sci 77: 1972-1982.

MYERS-SCHULZ B AND KOENIGS M. 2012. Functional anatomy of ventromedial prefrontal cortex: Implications for mood and anxiety disorders. Mol Psychiatry 17: 132141.

PAXINOS G AND WATSON C. 2007. The rat brain in stereotaxic coordinates. New York: Academic Press.
PRICE JL AND DREVETS WC. 2010. Neurocircuitry of mood disorders. Neuropsychopharmacology 35: 192-216.

PUIG MV AND GULLEDGE AT. 2011. Serotonin and Prefrontal Cortex Function: Neurons, Networks, and Circuits. Mol Neurobiol 44: 449-464.

PUIG MV, ARTIGAS F AND CELADA P. 2005. Modulation of the activity of pyramidal neurons in rat prefrontal cortex by raphe stimulation in vivo: involvement of serotonin and GABA. Cereb Cortex 15: 1-14.

RICHARD DM, DAWES MA, MATHIAS CW, ACHESON A, HILL-KAPTURCZAK N AND DOUGHERTY DM. 2009. L-Tryptophan: Basic Metabolic Functions, Behavioral Research and Therapeutic Indications. Int J Tryptophan Res 2: 45-60.

ROSSIF, MAIONE S AND BERRINO L. 1994. Periaqueductal gray area and cardiovascular function. Pharmacol Res 29: 27-36.

SILBER BY AND SCHMITT JA. 2010. Effects of tryptophan loading on human cognition, mood, and sleep. Neurosci Biobehav Rev 34: 387-407.

SIMPSON HB et al. 2008. A randomized, controlled trial of cognitive-behavioral therapy for augmenting pharmacotherapy in obsessive-compulsive disorder. Am J Psychiatry 165: 621-630.

STEIN DJ AND LOPEZ AG. 2011. Effects of escitalopram on sleep problems in patients with major depression or generalized anxiety disorder. Adv Ther 28: 1021-1037.

TITZE-DE-ALMEIDA R, SHIDA H, GUIMARÃES FS AND DEL-BEL EA. 1994. Stress-induced expression of the c-fos proto-oncogene in the hippocampal formation. Braz J Med Biol Res 27: 1083-1088.

VIALOU V et al. 2014. Prefrontal cortical circuit for depression- and anxiety-related behaviors mediated by cholecystokinin: role of $\triangle$ FosB. J Neurosci 34: 3878-3887.

WANG D, HE X, ZHAO Z, FENG Q, LIN R, SUN Y, DING T, XU F, LUO M AND ZHAN C. 2015. Whole-brain mapping of the direct inputs and axonal projections of POMC and AgRP neurons. Front Neuroanat 27: 9-40.

WURTMAN RJ AND WURTMAN JJ. 1986. Carbohydrate craving, obesity and brain serotonin. Appetite 7: 97-110.

YOUNG SN. 1996. Behavioral effects of dietary neurotransmitter precursors: basic and clinical aspects. Neurosci Biobehav Rev 20: 313-323.

YOUNG SN AND GAUTHIER S. 1981. Tryptophan availability and the control of 5-hydroxytryptamine and tryptamine synthesis in human CNS. Adv Exp Med Biol 133: $221-230$. 
